Research Article

\title{
Liver Resection Promotes (Regulates) Proinflammatory Cytokines in Patients with Hepatocellular Carcinoma
}

\author{
Farshid Fathi $\mathbb{D}^{1},{ }^{1}$ Behnam Sanei $\mathbb{D}^{2},{ }^{2}$ Mazdak Ganjalikhani Hakemi ${ }^{1},{ }^{1}$ Reza F. Saidi $\left(\mathbb{D},{ }^{3}\right.$ \\ and Abbas Rezaei $\mathbb{D}^{1}$ \\ ${ }^{1}$ Department of Immunology, School of Medicine, Isfahan University of Medical Sciences, Isfahan, Iran \\ ${ }^{2}$ Department of Hepatobiliary \& Pancreatic Surgery and Liver Transplantation, Al-Zahra Hospital, \\ Isfahan University of Medical Sciences, Isfahan, Iran \\ ${ }^{3}$ Division of Transplant Services, Department of Surgery, SUNY Upstate Medical University Syracuse, Syracuse, NY 13210, USA
}

Correspondence should be addressed to Reza F. Saidi; saidir@upstate.edu and Abbas Rezaei; ffathi19881367@gmail.com

Received 26 February 2021; Revised 15 April 2021; Accepted 20 April 2021; Published 26 April 2021

Academic Editor: Alessandro Granito

Copyright (C) 2021 Farshid Fathi et al. This is an open access article distributed under the Creative Commons Attribution License, which permits unrestricted use, distribution, and reproduction in any medium, provided the original work is properly cited.

Background. Several animal studies have shown the roles of cytokines in regulating liver regeneration following liver resection (LR), which is a type of surgery designed to remove cancerous tumors from the liver. This study investigated how the expressions and serum levels of some pro- and anti-inflammatory cytokines in patients with hepatocellular carcinoma (HCC) were changed during LR. Methods. Liver tissues from 15 patients with HCC were collected and the levels of interleukin-6 (IL-6), tumor necrosis factor-alpha (TNF- $\alpha$ ), IL- $1 \alpha$, IL-1 $\beta$, IL-10, and transforming growth factor-beta1 (TGF- $\beta 1$ ) were assessed using real-time PCR assay at different times before and after LR. The serum values of TNF- $\alpha$ and IL- 6 were also measured by ELISA. Results. After 60 and 90 minutes of LR, IL-6 gene expression was significantly increased $(P<0.001-0.05)$. The same trend was also observed in TNF- $\alpha$ expression after 90 minutes of LR $(P<0.01)$. No significant changes were observed in the expressions of IL- $1 \alpha$, IL- $1 \beta$, IL10 , and TGF- $\beta 1$ before and after LR. In addition, LR had significant effects on TNF- $\alpha$ and IL-6 serum levels $(P<0.05-0.0001)$. Conclusion. Our data provided further evidence to reveal that IL- 6 and TNF- $\alpha$ cytokines are critical to improve liver regeneration.

\section{Introduction}

Hepatocellular carcinoma (HCC) is one of the most common malignant tumors worldwide which predominantly occurs in subjects with chronic liver diseases [1]. HCC is responsible for approximately 1000000 deaths annually, making it the third leading cause of cancer death [2]. Recent evidence from different countries has shown that the incidence of HCC is rising [3-5]. Its causes have not been identified yet, but some factors are proposed for increasing the risk for the susceptibility, including hepatitis B and C infections, liver cirrhosis, alcohol consumption, obesity and diabetes, iron storage disease, aflatoxin toxicity, fatty liver disease, and drug-induced liver injury [1]. The initiation and progression of this disease are associated with genetic, environmental, and immunological factors. Some therapies have been proposed to treat HCC, including liver resection (LR), liver transplantation, stem cell transplantation, and artificial liver support systems [6]. In patients who were diagnosed at early stages (Barcelona Clinic Liver Cancer Stage 0 or A-BCLC 0/A), LR and local ablation are potentially effective and increase life expectancy remarkably [2].

In normal condition, hepatocytes and cholangiocytes stay in the G0 phase of the cell cycle and indicate minimal turnover, but in response to various stimulations such as toxic injury, infections, and LR, they proliferate to compensate for the lost cells, a process called liver regeneration $[7,8]$. Although the precise mechanism of liver regeneration is not well understood, extensive data from the literature have demonstrated that the immune system plays an important role in the initiation and termination of liver regeneration through pro- and anti-inflammatory mediators such as cytokines, complement, and chemokines $[9,10]$. Several studies have shown that cytokines stimulate hepatocytes to start the cell cycle $[11,12]$. Others have indicated 
that cytokines contribute to recruit immune cells such as T cells, B cells, macrophages, NKT, and NK cells into liver tissue to improve liver regeneration [13]. Several cytokines and chemokines such as IL- 1 , IL- 6 , TNF- $\alpha$, IL-10, TGF- $\beta$, CCL2, and CCL5 have been reported for their contributions in liver regeneration [14-16].

Some studies have emphasized the roles of IL- 6 and soluble IL-6 receptor in liver regeneration [17]. Some animal studies have revealed that IL-6-deficient mice had liver failure and defective hepatocyte regeneration in which a single preoperative dose of IL- 6 prevented liver damages through returning gene expression and hepatocyte proliferation to near normal [16]. Moreover, it is demonstrated that IL- 6 and TNF- $\alpha$ had pivotal roles in early graft regeneration in patients who underwent living donor liver transplantation (LDLT) [18]. These findings suggest a possible therapeutic potential for IL- 6 and TNF- $\alpha$ to recover liver functions in clinical situations associated with liver regeneration such as acute hepatic failure or resection of chronically damaged liver tissue.

Some cells have been proposed as the cell sources of the most important cytokines for liver regeneration, including hepatocytes, hepatic stellate cells, infiltrated immune cells, and cancer-associated fibroblasts [10]. Numerous reports have indicated the role of pro- and anti-inflammatory cytokines in liver regeneration in animal studies [19]. To our knowledge, there is no report showing the expression levels of these cytokines in patients with HCC after LR. This study was therefore focused on investigating the gene expressions of IL- $1 \alpha$, IL- $1 \beta$, IL- 6 , and TNF- $\alpha$ as pro-inflammatory and TGF- $\beta 1$ and IL-10 as anti-inflammatory cytokines in patients with HCC before and after LR.

\section{Material and Methods}

2.1. Study Population. The study population consisted of 15 individuals referred to surgery centers of Al-Zahra and Sina hospitals in Isfahan and Tehran, respectively. This work was conducted from April 2019 to April 2020. The HCC stage was determined by a specialist according to the eighth edition of the Cancer Staging Manual by the American Joint Committee on Cancer (AJCC) [20]. All these patients have well-compensated cirrhosis with normal liver function tests. The sampling was carried out at least one month after the last radiotherapy, chemotherapy, and other therapeutic approaches. None of the patients was on preoperative radiotherapy, chemotherapy, and other medical interventions, which could affect the immune system and cytokine productions at the time of the sampling. Experimental protocols were approved by the Ethics Committee of Tehran University of Medical Sciences (ethic code: IR.TUMS.VCR.REC1396.4790) and performed according to the Declaration of Helsinki. All participants were informed before entering the study and informed consent was obtained from the subjects.

2.2. Sample Collection. LR was performed by a surgical team, and approximately $70 \%$ of the total liver was removed. Liver tissues were collected from patients several times following surgical resection. Briefly, in the first place, the sample was obtained after starting surgery opened the abdominal cavity and before LR. Malignant tissues were removed and remained liver tissue was subjected to sampling $(30,60$, and 90 minutes after LR). The samples were stored at $-196^{\circ} \mathrm{C}$ for the next experiments.

\subsection{RNA Extraction and Complementary Deoxyribonucleic} Acid (cDNA) Synthesis. The total RNAs were isolated from the frozen liver tissues using an RNA isolation kit based on the manufacturer's instructions (Yekta Tajhiz, Iran). The quantity and purity of the extracted RNAs were determined by NanoDrop (Thermo Fisher Scientific, USA) and run in $1 \%$ agarose gel. The cDNA synthesis was performed using a reverse transcription kit (Biofact, South Korea) according to the manufacturer's instructions. Briefly, the first strand of cDNA was synthesized in the total volume of $10 \mu \mathrm{l}$, containing $1 \mu \mathrm{l}(1 \mathrm{ng})$ of mRNA, $1 \mu \mathrm{l}$ of RT enzyme, $4 \mu \mathrm{l}$ of $10 \mathrm{X}$ buffer, $2 \mu \mathrm{l}$ of random hexamer and poly-A (dT) primers, and $2 \mu \mathrm{l}$ of the nuclease-free water. Then, the reaction mixture was incubated at $42^{\circ} \mathrm{C}$ for 1 hour. The cDNA was stored at $-80^{\circ} \mathrm{C}$ for use in real-time polymerase chain reaction (PCR).

2.4. Real-Time PCR. To assess the mRNA levels of IL- $1 \alpha$, IL$1 \beta$, IL-6, IL-10, TNF- $\alpha$, and TGF- $\beta$, real-time PCR was carried out using an ABI7700 machine (Applied Biosystems, Foster City, USA). Each reaction was initiated at $95^{\circ} \mathrm{C}$ for 10 minutes followed by 40 cycles of $95^{\circ} \mathrm{C}$ for 30 seconds and $60^{\circ} \mathrm{C}$ for 40 seconds. All analyses were done in triplicate. Real-time PCR was carried out in a reaction mixture $(10 \mu \mathrm{L})$ consisted of $4 \mu \mathrm{L}$ of $2 \mathrm{X}$ Real-Time PCR master mix (SYBR ${ }^{\circledR}$ Premix Ex Taq ${ }^{\mathrm{TM}}$ II; Bio Fact, Korea), $2 \mu \mathrm{L}$ of forward and reverse primers ( $10 \mathrm{pM}), 1 \mu \mathrm{L}$ of cDNA template, $2.7 \mu \mathrm{L}$ of DNase-RNase free water, and $0.3 \mu \mathrm{L}$ of ROX. The temperature and cycling parameters mentioned above were used to determine the expression levels of IL- $1 \alpha$, IL-1 $\beta$, IL-6, IL-10, TNF- $\alpha$, and TGF- $\beta 1$. The melting curves were automatically generated in the $60^{\circ} \mathrm{C}$ to $95^{\circ} \mathrm{C}$ temperature range. The primer sequences and other information of real-time PCR are shown in Table 1. The expression levels of the genes were normalized to the expression levels of $\beta$-actin and glyceraldehyde-3-phosphate dehydrogenase (GAPDH) genes as the endogenous controls. The expression levels of the genes were calculated according to the $2^{-\Delta \Delta C T}$ method [21]. The primers were designed by AlleleID 7.5 software (Premier Biosoft Intl, Palo Alto, CA, USA) and purchased from Takapou Zist (Iran).

2.5. Cytokine Assay. To evaluate the effect of LR on the serum levels of cytokines in HCC patients, peripheral blood samples were obtained from patients before and after 30, 60, 90, and 180 minutes of LR. The serum levels of TNF- $\alpha$ and IL-6 were measured using an enzyme-linked immunosorbent assay (ELISA) kit according to the manufacturer's protocol (Karmania Pars Gene, Iran). All assays were performed in duplicate. 
TAвLe 1: Primer sequences and other information used to determine the expressions of pro- and anti-inflammatory cytokines.

\begin{tabular}{|c|c|c|c|}
\hline Gene & Primer sequence & Amplicon size (bp) & Annealing temperatures $\left({ }^{\circ} \mathrm{C}\right)$ \\
\hline IL- $1 \alpha$ & $\begin{array}{c}\text { Forward }\left(5^{\prime}-3^{\prime}\right) \\
\text { GTGACTGCCCAAGATGAAGACC } \\
\text { Reverse }\left(5^{\prime}-3^{\prime}\right) \\
\text { TCCCAGAAGAAGAGGAGGTTGG }\end{array}$ & 101 & 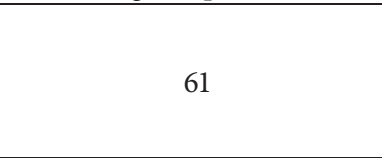 \\
\hline IL-6 & $\begin{array}{c}\text { Forward }\left(5^{\prime}-3^{\prime}\right) \\
\text { AGAGTAACATGTGTGAAAGCAGCA } \\
\text { Reverse }\left(5^{\prime}-3^{\prime}\right) \\
\text { TGATGATTTTCACCAGGCAAGTCT }\end{array}$ & 129 & 61 \\
\hline IL- $1 \beta$ & $\begin{array}{c}\text { Forward }\left(5^{\prime}-3^{\prime}\right) \\
\text { AGGGACAGGATATGGAGCAACA } \\
\text { Reverse }\left(5^{\prime}-3^{\prime}\right) \\
\text { CTTTCAACACGCAGGACAGGT }\end{array}$ & 129 & 61 \\
\hline IL-10 & $\begin{array}{c}\text { Forward }\left(5^{\prime}-3^{\prime}\right) \\
\text { TCAAGGCGCATGTGAACTCC } \\
\text { Reverse }\left(5^{\prime}-3^{\prime}\right) \\
\text { CATTCTTCACCTGCTCCACGG }\end{array}$ & 120 & 61 \\
\hline TGF- $\beta 1$ & $\begin{array}{c}\text { Forward }\left(5^{\prime}-3^{\prime}\right) \\
\text { CATGCCAACTTCTGCCTCGG } \\
\text { Reverse }\left(5^{\prime}-3^{\prime}\right) \\
\text { TGGTTGTACAGGGCCAGGAC }\end{array}$ & 83 & 61 \\
\hline TNF- $\alpha$ & $\begin{array}{c}\text { Forward }\left(5^{\prime}-3^{\prime}\right) \\
\text { GACCTCTCTCTAATCAGCCCTCT } \\
\text { Reverse }\left(5^{\prime}-3^{\prime}\right) \\
\text { CTGGTTATCTCTCAGCTCCACG }\end{array}$ & 174 & 61 \\
\hline
\end{tabular}

2.6. Statistical Analysis. Data analysis was performed by GraphPad Prism 6 (GraphPad Software, USA). The results are shown as the standard error of the mean (SEM). The normal distributions of the data were determined by Kolmogorov-Smirnov test. One-way ANOVA and paired $t$-tests were used to compare the groups with normal distribution. Data with nonparametric distribution were analyzed using Mann-Whitney and Kruskal-Wallis tests. The significance level was considered as $P<0.05$.

\section{Results}

3.1. Subject Descriptions. A total of 15 individuals with HCC ( 8 males and 7 females, mean age: $60 \pm 2.59$, mean \pm standard deviation, range: 56 to 66 years) were enrolled in this study (Table 2). All patients with HCC had a primary tumor and most of them were in stage IIIA (46.66\%, Table 2). According to Barcelona Clinic Liver Cancer (BCLC) system, all our patients were in 0 or A stage with a single tumor or up to 3 nodules smaller than $3 \mathrm{~cm}$ or Child-Pugh-Turcotte (CPT A). Table 2 depicts the clinicopathological characteristics of HCC subjects.

3.2. The Impacts of LR on the Expression Levels and Serum Levels of Proinflammatory Cytokines in HCC Patients. To determine the effect of LR on the expression levels of TNF- $\alpha$, IL- $1 \alpha$, IL- $1 \beta$, and IL- 6 , the levels of these cytokines were assessed several times using the real-time PCR method. The results showed that the expressions of IL- 6 and TNF- $\alpha$ were increased after LR. After 60 and 90 minutes of LR, IL- 6 gene expression was significantly increased $(P<0.001-0.05$,
Figure 1(a)). The means of expression changes were 3.9- and 2.1-fold after 60 and 90 minutes of LR, respectively (Figure 1(a)). The same trend was also observed in TNF- $\alpha$ expression after 90 minutes of $\operatorname{LR}(P<0.01$, Figure $1(b))$. The mean of expression change was 3.2-fold after 90 minutes. No significant changes in the expressions of IL- $1 \alpha$ and IL- $1 \beta$ were observed before and after LR (Figures 1(c) and 1(d)).

3.3. The Expression Levels of Anti-Inflammatory Cytokines in HCC Patients before and after LR. The results of the real-time PCR method indicated that LR did not affect IL-10 and TGF$\beta 1$ expression levels. There were no significant differences in the expression levels of these cytokines before and after LR (Figures 2(e) and 2(f)).

3.4. The Impact of LR on the Serum Levels of Proinflammatory Cytokines. To further confirm the possible effect of LR on expression levels of cytokines, the serum levels of cytokines, whose expressions were affected by LR, were studied before and after 30, 60, 90, and 180 minutes of LR. Similar trends were observed in the serum values of TNF- $\alpha$ and IL- 6 (Figures 2(a) and 2(b)). LR had a potent impact on elevating TNF- $\alpha$ and IL-6 levels $(P<0.05-0.0001$, Figures $2(\mathrm{a})$ and 2(b)).

\section{Discussion}

Liver regeneration is a process to return to the normal size of the liver after injury and surgery [22]. Under normal condition, cell turnover rarely occurs in the liver, but two-thirds $\mathrm{LR}$, as the most common method to remove malignant liver 
TABLE 2: The clinicopathological characteristics of participants.

\begin{tabular}{lc}
\hline Age $($ mean \pm SD) & $60 \pm 2.59$ \\
Gender & Female: $7(46.66)$ \\
Tumor type & Male: $8(53.33)$ \\
TNM $*$ & HCC: $15(100 \%)$ \\
$\quad$ Primary tumor & T2: $4(26.66 \%) ;$ T3: $7(46.66 \%) ;$ T4: \\
$\quad$ Regional lymph & $4(26.66 \%)$ \\
nodes & $0(0.0 \%)$ \\
Distant metastasis & $0(0.0 \%)$ \\
& II: $4(26.66 \%)$ \\
Stage & IIIA: $7(46.66 \%)$ \\
& IIIB: $4(26.66 \%)$ \\
Tumor size & $<2: 6(40 \%)$ \\
& $\leq 2-5 \leq: 7(46.66 \%)$ \\
Hepatitis B & $5>2(13.34 \%)$ \\
Smoking history & $2(13.34 \%)$ \\
Alcohol consumption & $6(40 \%)$ \\
WBC & $44(26.66 \%)$ \\
Hb (g/dl) & $9766 \pm 1240$ \\
Hct (\%) & $11.67 \pm 1.54$ \\
FBS (mg/dl) & $39.45 \pm 3.18$ \\
Creatinine (mg/dl) & $96.11 \pm 7.9$ \\
BUN (mg/dl) & $0.96 \pm 0.16$ \\
Urea (mg/dl) & $15.56 \pm 3.19$ \\
AST (U/L) & $9.67 \pm 2.54$ \\
ALT(U/L) & $36.43 \pm 3.12$ \\
Albumin (g/dl) & $34.8 \pm 4.39$ \\
Total bilirubin (mg/dl) & $3.86 \pm 0.81$ \\
PT (seconds) & $1.06 \pm 0.4$ \\
PTT (seconds) & $13.5 \pm 1.67$ \\
\hline & $34.1 \pm 3.89$ \\
\hline &
\end{tabular}

* TNM staging based on AJCC 8th edition. HCC: hepatocellular carcinoma; Hb: hemoglobin; Hct; hematocrit; FBS: fasting blood sugar; BUN: blood urea nitrogen; AST: aspartate aminotransferase; ALT: alanine transaminase; PT: prothrombin time; PTT: partial thromboplastin time.

tumors, induces the proliferation of mature hepatocytes [23-25]. Although there are several animal studies pointing to the roles of cytokines in liver regeneration after LR [26], this study, for the first time, investigated how LR influences the gene expressions of IL- $1 \alpha$, IL- $1 \beta$, IL- 6 , TNF- $\alpha$, IL- 10 , and TGF- $\beta$ in HCC patients.

Our results indicated that the expressions and serum levels of IL- 6 and TNF- $\alpha$ after LR were significantly increased in comparison with their levels before LR. Transcript levels of IL- 6 and TNF- $\alpha$ were significantly increased after 60 and 90 minutes of LR, respectively. In agreement with these findings, previous studies have revealed that the serum levels of hepatocyte growth factor (HGF) and IL-6 increased at similar rates during the first 24 hours after LR in patients with focal nodular hyperplasia and hepatic hemangioma [27]. Several studies have declared that inflammatory responses induced upon LR were immediately needed for liver regeneration [28]. In line with this notion, animal studies have shown that approximately $70 \%$ of IL- 6 gene knocking out mice failed to have liver regeneration [29]. It is reported that Kupffer cells as a tissue-resident macrophage are the main source of cytokines associated with liver regeneration, including IL-6, TNF- $\alpha$, IL10 , and TGF- $\beta 1$ [30-32]. Therefore, these cells are critical for hepatocyte regeneration after LR. Animal studies have revealed that Kupffer cell depletion affects hepatic IL-6, IL-10, TNF- $\alpha$, and TGF- $\beta 1$ mRNA syntheses and thereby delays liver regeneration after LR [26]. Yasuhiro et al. showed that knock out of TNFR-1 gene led to defect in liver regeneration after CCL4-induced acute liver failure [33]. These findings are consistent with our results pointing to the necessity of IL-6 and TNF- $\alpha$ for liver regeneration. However, they are in contrast with other studies showing the depletions of proinflammatory genes did not affect liver regeneration. An animal study conducted by Fujita et al. declared that TNF gene depletion had no effect on liver regeneration [34]. However, it negatively affected liver function and neutrophil activation [34]. Other results of the current study revealed there are no significant differences in gene expressions of IL$1 \alpha$, IL- $1 \beta$, IL- 10 , and TGF- $\beta 1$ before and after LR. In contrast to our data, some animal studies have demonstrated the role of IL-1 in liver regeneration after LR. Ma et al. indicated that downregulation of IL- $1 \beta$ gene by siRNA could improve liver regeneration in rates after CCL4-induced acute liver failure [35]. Another study on rats has shown that the reduced serum level of IL-1 $\beta$ promoted liver regeneration after liver failure [36]. In addition, others have revealed that IL-1 receptor antagonist (IL-1R $\alpha$ ) significantly reduced inflammation after LR and enhanced liver regeneration [37]. Moreover, LR is the mainstay of curative treatment and health-giving treatment for HCC, and the long-term survival of patients still remains undesirable since recurrence happens in about $54 \%$ of patients who underwent resection $[38,39]$. Recurrence after LR is highly associated with aggressive tumor characteristics, size of the tumor, presence of cirrhosis, Child-Pugh classification, alcohol consumption, and smoking [40].On the other hand, all HCC patients are not suitable for LR [41]. Ascites and uncorrectable coagulopathy are two major factors that reduce the number of candidates for surgery; furthermore, radiofrequency ablation has been suggested by the researcher as an alternative therapy for these CPT A and B HCC patients, and 3 -year survival of patients reached up to $65 \%$ after it [42]. LR and radiofrequency ablation liver transplantation is a curative option for HCC patients, and there are types of adjuvant therapy for CPT A and B HCC patients, for instance, Transarterial chemoembolization (TACE), transarterial radioembolization (TARE), sorafenib, antiviral therapy, and IFN $[42,43]$. Although sorafenib is the only approved drug for HCC treatment, a notable number of sorafenib-treated patients experience disease progression. Furthermore, investigators introduced second-line systemic therapy instead of sorafenib [44]. Capecitabine (Xeloda ${ }^{\circledR}$, Roche) is a replacement for sorafenib, and studies by Granito et al. showed that it is a safe and effective treatment as a second-line therapy in patients unresponsive to sorafenib [45]. On the other hand, Xia et al. showed adjuvant therapy with capecitabine after LR significantly decreases the risk of HCC [46]. Although patient's outcome is critical after LR, in this study we did not follow up the patients to access the survival or recurrence rate and our focus was regeneration.

Also in an attempt to determine the effect of LR on the expression levels of cytokines involved in controlling inflammation, the levels of IL- 10 and TGF- $\beta 1$ were investigated. In contrast with other reports showing the levels of anti- 


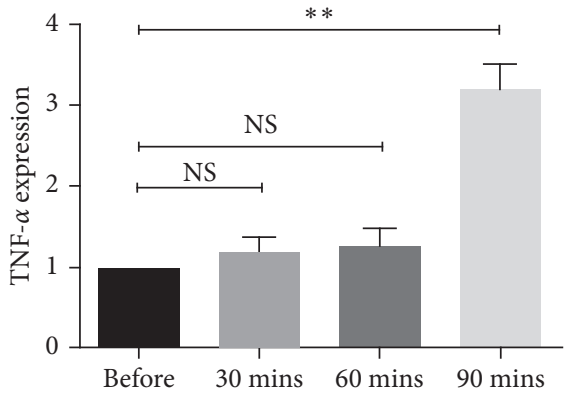

(a)

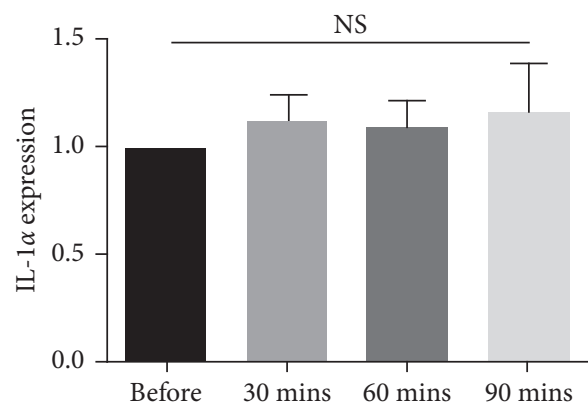

(c)

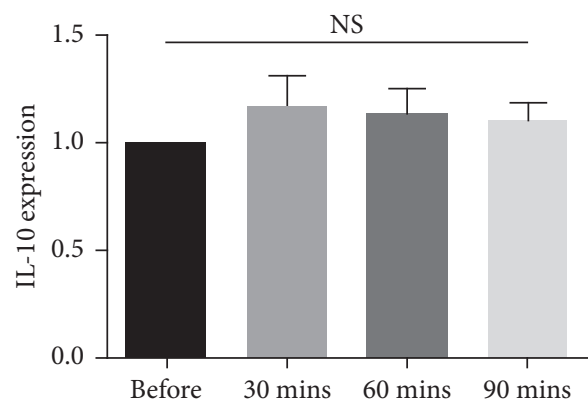

(e)

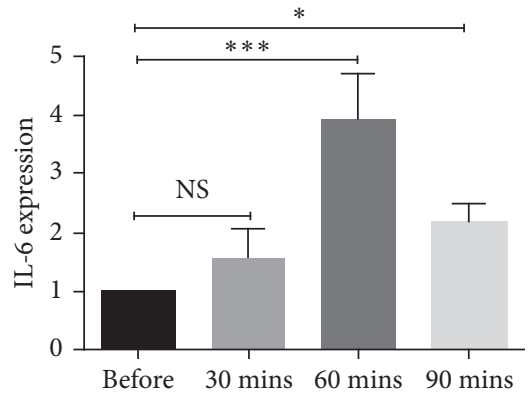

(b)

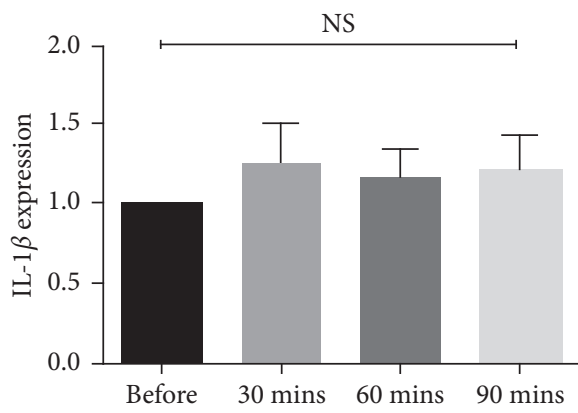

(d)

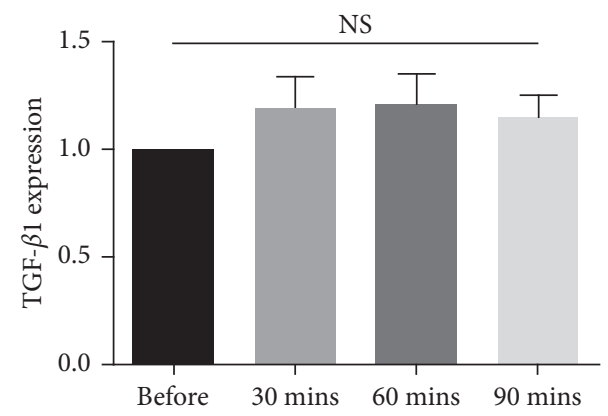

(f)

Figure 1: The effect of liver regeneration on the expression levels of proinflammatory and anti-inflammatory cytokines in HCC patients. The expressions of (a) IL-6, (b) TNF- $\alpha$, (c) IL- $1 \alpha$, (d) IL- $1 \beta$, (e) IL-10, and (f) TGF- $\beta 1$ were determined by real-time PCR assay before and after LR. All data are shown as mean \pm SEM. The depicted results are representative of 15 independent experiments. NS indicates that the differences in the expression levels are not statistically significant. Asterisks indicate that the differences in the expression levels are statistically significant. ${ }^{*} P<0.05,{ }^{* *} P<0.01$, and ${ }^{* * *} P<0.001$.

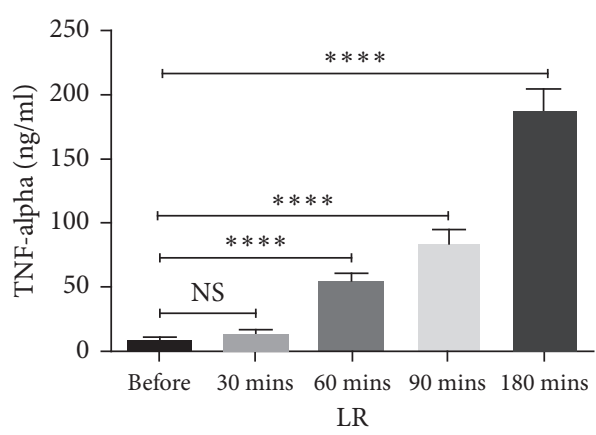

(a)

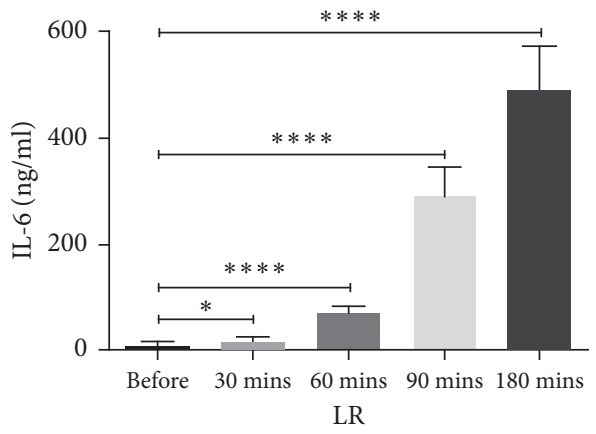

(b)

FIGURE 2: The effect of liver regeneration on the serum concentrations of proinflammatory cytokines in HCC patients. The levels of TNF- $\alpha$ and IL- 6 in patients with HCC were measured before and after liver regeneration using ELISA ((a) and (b)). The depicted results are representative of 15 independent experiments for HCC subjects. All data are shown as mean \pm SEM. ${ }^{*} P<0.05$ and ${ }^{* * *} P<0.001$. 
inflammatory cytokines were increased following LR, the results of the present study showed that LR had no significant effect on TGF- $\beta$ and IL-10 expressions. Shin et al. in a study on rats reported that IL-10 expression along with other cytokines (TNF, IL-1, and IL-6) significantly increased within three hours after LR [47]. Furthermore, the authors have revealed that inhibition of IL-10 production by Kupffer cell depletion enhanced the expression of TNF- $\alpha$ in the regeneration of rat liver [47] and induced a cytokine cascade which promoted hepatocyte proliferation after 70\% LR. In line with the expression levels of other anti-inflammatory cytokines after LR, Picardo et al. indicated that the increase in TGF- $\beta$ mRNA level occurred following TNF- $\alpha$, IL-6, and HGF after LR [48]. TGF- $\beta 1$, like IL-10, exerts an inhibitory effect on hepatocyte proliferation and thereby plays an important role in the termination of liver regeneration $[9,25,48]$. It is reported that TGF- $\beta$ signaling in hepatocytes inhibited the proliferative responses after LR [49]. Others have revealed that TGF- $\beta 1$ inhibition with anti-TGF- $\beta 1$ antibody after LR in dimethylnitrosamine-treated cirrhotic and biliary-obstructed rats improved liver regeneration both morphologically and functionally $[50,51]$. Therefore, the reduction in the levels of TGF- $\alpha$ and TGF- $\beta$ receptors following LR may be a compensatory response to enhance liver regeneration [52]. However, these discrepancies observed between our results and previous studies may be related to the sample sizes, sample types, and sampling times used in different studies.

\section{Conclusion}

The results of the current study, consistent with animal studies, provide further evidence to reveal that the production of proinflammatory cytokines was increased after LR and may have a role in regulating liver regeneration. However, a limitation of the study was the lack of healthy subjects as a control group. Therefore, this limitation should be considered to confirm these findings in future studies.

\section{Data Availability}

The data used to support the findings of this study are available from the corresponding author upon request.

\section{Conflicts of Interest}

The authors declare no conflicts of interest.

\section{Acknowledgments}

The authors thank all individuals who participated in this study. This work was financially supported by Medical University of Isfahan (MUI) and Tehran University of Medical Sciences (TUMS) (Grant no. 397261).

\section{References}

[1] A. M. Di Bisceglie, V. K. Rustgi, J. H. Hoofnagle, G. M. Dusheiko, and M. T. Lotze, "Hepatocellular carcinoma," Annals of Internal Medicine, vol. 108, no. 3, pp. 390-401, 1988.
[2] J. Bruix, M. Reig, and M. Sherman, "Evidence-based diagnosis, staging, and treatment of patients with hepatocellular carcinoma," Gastroenterology, vol. 150, no. 4, pp. 835-853, 2016.

[3] J. Bruix and M. Sherman, "Management of hepatocellular carcinoma: an update," Hepatology, vol. 53, no. 3, pp. 1020-1022, 2011.

[4] H. B. El-Serag and A. C. Mason, "Rising incidence of hepatocellular carcinoma in the United States," New England Journal of Medicine, vol. 340, no. 10, pp. 745-750, 1999.

[5] D. M. Parkin, F. Bray, J. Ferlay, and P. Pisani, "Estimating the world cancer burden: globocan 2000," International Journal of Cancer, vol. 94, no. 2, pp. 153-156, 2001.

[6] J. K. Heimbach, L. M. Kulik, R. S. Finn et al., "AASLD guidelines for the treatment of hepatocellular carcinoma," Hepatology, vol. 67, no. 1, pp. 358-380, 2018.

[7] C. Hu and L. Li, "In vitro culture of isolated primary hepatocytes and stem cell-derived hepatocyte-like cells for liver regeneration," Protein \& Cell, vol. 6, no. 8, pp. 562-574, 2015.

[8] M. Canbek, M. Uyanoglu, S. Canbek et al., "The effect of geraniol on liver regeneration after hepatectomy in rats," In Vivo, vol. 31, no. 2, pp. 209-214, 2017.

[9] S. V. Sasturkar, P. David, S. Sharma, S. K. Sarin, N. Trehanpati, and V. Pamecha, "Serial changes of cytokines and growth factors in peripheral circulation after right lobe donor hepatectomy," Liver Transplantation, vol. 22, no. 3, pp. 344-351, 2016.

[10] C. Hu, Z. Wu, and L. Li, "Mesenchymal stromal cells promote liver regeneration through regulation of immune cells," International Journal of Biological Sciences, vol. 16, no. 5, pp. 893-903, 2020.

[11] V. Bieghs and C. Trautwein, "The innate immune response during liver inflammation and metabolic disease," Trends in Immunology, vol. 34, no. 9, pp. 446-452, 2013.

[12] A. I. Su, L. G. Guidotti, J. P. Pezacki, F. V. Chisari, and P. G. Schultz, "Gene expression during the priming phase of liver regeneration after partial hepatectomy in mice," Proceedings of the National Academy of Sciences, vol. 99, no. 17, pp. 11181-11186, 2002.

[13] J. Wang and P. Kubes, "A reservoir of mature cavity macrophages that can rapidly invade visceral organs to affect tissue repair," Cell, vol. 165, no. 3, pp. 668-678, 2016.

[14] P. Melgar-Lesmes and E. R. Edelman, "Monocyte-endothelial cell interactions in the regulation of vascular sprouting and liver regeneration in mouse," Journal of Hepatology, vol. 63, no. 4, pp. 917-925, 2015.

[15] C. Ju and F. Tacke, "Hepatic macrophages in homeostasis and liver diseases: from pathogenesis to novel therapeutic strategies," Cellular \& Molecular Immunology, vol. 13, no. 3, pp. 316-327, 2016.

[16] D. E. Cressman, L. E. Greenbaum, R. A. DeAngelis et al., "Liver failure and defective hepatocyte regeneration in interleukin-6-deficient mice," Science, vol. 274, no. 5291, pp. 1379-1383, 1996.

[17] M. Peters, G. Blinn, T. Jostock et al., "Combined interleukin 6 and soluble interleukin 6 receptor accelerates murine liver regeneration," Gastroenterology, vol. 119, no. 6, pp. 1663-1671, 2000.

[18] M. S. Chae, K. U. Moon, H. S. Chung et al., "Serum interleukin- 6 and tumor necrosis factor- $\alpha$ are associated with early graft regeneration after living donor liver transplantation," PLoS One, vol. 13, no. 4, Article ID e0195262, 2018. 
[19] B. Gao, "Hepatoprotective and anti-inflammatory cytokines in alcoholic liver disease," Journal of Gastroenterology and Hepatology, vol. 27, pp. 89-93, 2012.

[20] M. R. Weiser, "AJCC 8th edition: colorectal cancer," Annals of Surgical Oncology, vol. 25, no. 6, pp. 1454-1455, 2018.

[21] K. J. Livak and T. D. Schmittgen, "Analysis of relative gene expression data using real-time quantitative PCR and the $2^{-\Delta \Delta \mathrm{CT}}$ method," Methods, vol. 25, no. 4, pp. 402-408, 2001.

[22] G. K. Michalopoulos, "Liver regeneration," The Liver, vol. 6, pp. 566-584, 2020.

[23] K. Abshagen, C. Eipel, and B. Vollmar, "A critical appraisal of the hemodynamic signal driving liver regeneration," Langenbeck's Archives of Surgery, vol. 397, no. 4, pp. 579-590, 2012.

[24] I. Anwar, U. Ashfaq, and Z. Shaukat, "Therapeutic potential of umbilical cord stem cells for liver regeneration," Current Stem Cell Research \& Therapy, vol. 15, no. 3, pp. 219-232, 2020.

[25] G. K. Michalopoulos, "Liver regeneration after partial hepatectomy," The American Journal of Pathology, vol. 176, no. 1, pp. 2-13, 2010.

[26] C. Meijer, M. J. Wiezer, A. M. Diehl et al., "Kupffer cell depletion by CI2MDP-liposomes alters hepatic cytokine expression and delays liver regeneration after partial hepatectomy," Liver International, vol. 20, no. 1, pp. 66-77, 2000.

[27] O. Kornasiewicz, M. Grạt, K. Dudek et al., "Serum levels of HGF, IL-6, and TGF- $\alpha$ after benign liver tumor resection," Advances in Medical Sciences, vol. 60, no. 1, pp. 173-177, 2015.

[28] S. Yin, H. Wang, O. Park, W. Wei, J. Shen, and B. Gao, "Enhanced liver regeneration in IL-10-deficient mice after partial hepatectomy via stimulating inflammatory response and activating hepatocyte STAT3," The American Journal of Pathology, vol. 178, no. 4, pp. 1614-1621, 2011.

[29] W. Li, X. Liang, C. Kellendonk, V. Poli, and R. Taub, "STAT3 contributes to the mitogenic response of hepatocytes during liver regeneration," Journal of Biological Chemistry, vol. 277, no. 32, pp. 28411-28417, 2002.

[30] Y. Yamada, I. Kirillova, J. J. Peschon, and N. Fausto, "Initiation of liver growth by tumor necrosis factor: deficient liver regeneration in mice lacking type I tumor necrosis factor receptor," Proceedings of the National Academy of Sciences, vol. 94, no. 4, pp. 1441-1446, 1997.

[31] P. Pediaditakis, J. C. Lopez-Talavera, B. Petersen, S. P. Monga, and G. K. Michalopoulos, "The processing and utilization of hepatocyte growth factor/scatter factor following partial hepatectomy in the rat," Hepatology, vol. 34, no. 4, pp. 688-693, 2001.

[32] Z.-Y. Zheng, S.-Y. Weng, and Y. Yu, "Signal molecule-mediated hepatic cell communicationduring liver regeneration," World Journal of Gastroenterology, vol. 15, no. 46, p. 5776, 2009.

[33] Y. Yamada and N. Fausto, "Deficient liver regeneration after carbon tetrachloride injury in mice lacking type 1 but not type 2 tumor necrosis factor receptor," The American Journal of Pathology, vol. 152, no. 6, pp. 1577-89, 1998.

[34] J. Fujita, M. W. Marino, H. Wada et al., "Effect of TNF gene depletion on liver regeneration after partial hepatectomy in mice," Surgery, vol. 129, no. 1, pp. 48-54, 2001.

[35] H. Ma, X. Shi, X. Yuan, and Y. Ding, "IL- $1 \beta$ siRNA adenovirus benefits liver regeneration by improving mesenchymal stem cells survival after acute liver failure," Annals of Hepatology, vol. 15, no. 2, pp. 260-270, 2016.

[36] N. Wang, Z. Wang, H. Sun, X. Shi, Y. Zhang, and Q. Liu, "Augmenter of liver regeneration improves therapeutic effect of hepatocyte homotransplantation in acute liver failure rats,"
International Immunopharmacology, vol. 15, no. 2, pp. 325332, 2013.

[37] M. Boermeester, "Endotoxin and interleukin-1 related hepatic inflammatory response promotes liver failure after partial hepatectomy*1," Hepatology, vol. 22, no. 5, pp. 1499-1506, 1995.

[38] F. Foerster, M. Hoppe-Lotichius, J. Vollmar et al., "Long-term observation of hepatocellular carcinoma recurrence after liver transplantation at a European transplantation centre," United European Gastroenterology Journal, vol. 7, no. 6, pp. 838-849, 2019.

[39] X.-F. Xu, H. Xing, J. Han et al., "Risk factors, patterns, and outcomes of late recurrence after liver resection for hepatocellular carcinoma," JAMA Surgery, vol. 154, no. 3, pp. 209-217, 2019.

[40] T. Sempokuya and L. L. Wong, "Ten-year survival and recurrence of hepatocellular cancer," Hepatoma Research, vol. 5, 2019.

[41] Y.-s. Kim, H. K. Lim, H. Rhim, and M. W. Lee, "Ablation of hepatocellular carcinoma," Best Practice \& Research Clinical Gastroenterology, vol. 28, no. 5, pp. 897-908, 2014.

[42] A. Granito and L. Bolondi, "Non-transplant therapies for patients with hepatocellular carcinoma and child-pugh-turcotte class B cirrhosis," The Lancet Oncology, vol. 18, no. 2, pp. e101-e112, 2017.

[43] A. Gramenzi, R. Golfieri, C. Mosconi et al., "Yttrium-90 radioembolization vs sorafenib for intermediate-locally advanced hepatocellular carcinoma: a cohort study with propensity score analysis," Liver International, vol. 35, no. 3, pp. 1036-1047, 2015.

[44] S. Ogasawara, T. Chiba, Y. Ooka et al., "Post-progression survival in patients with advanced hepatocellular carcinoma resistant to sorafenib," Investigational New Drugs, vol. 34, no. 2, pp. 255-260, 2016.

[45] A. Granito, S. Marinelli, E. Terzi et al., "Metronomic capecitabine as second-line treatment in hepatocellular carcinoma after sorafenib failure," Digestive and Liver Disease, vol. 47, no. 6, pp. 518-522, 2015.

[46] Y. Xia, Y. Qiu, J. Li et al., “Adjuvant therapy with capecitabine postpones recurrence of hepatocellular carcinoma after curative resection: a randomized controlled trial," Annals of Surgical Oncology, vol. 17, no. 12, pp. 3137-3144, 2010.

[47] R. M. Rai, S. Loffreda, C. L. Karp, S. Yang, H. Lin, and A. M. Diehl, "Kupffer cell depletion abolishes induction of interleukin-10 and permits sustained overexpression of tumor necrosis factor alpha messenger RNA in the regenerating rat liver," Hepatology, vol. 25, no. 4, pp. 889-895, 1997.

[48] A. Picardo, H. M. Karpoff, B. Ng, J. Lee, M. F. Brennan, and Y. Fong, "Partial hepatectomy accelerates local tumor growth: potential roles of local cytokine activation," Surgery, vol. 124, no. 1, pp. 57-64, 1998.

[49] J. Romero-Gallo, E. G. Sozmen, A. Chytil et al., "Inactivation of TGF- $\beta$ signaling in hepatocytes results in an increased proliferative response after partial hepatectomy," Oncogene, vol. 24, no. 18, pp. 3028-3041, 2005.

[50] M. A. Deneme, E. Ok, A. Akcan, H. Akyildiz, I. Soyuer, and S. Muhtaroglu, "Single dose of anti-transforming growth factor- $\beta 1$ monoclonal antibody enhances liver regeneration after partial hepatectomy in biliary-obstructed rats," Journal of Surgical Research, vol. 136, no. 2, pp. 280-287, 2006.

[51] K. Ohara and M. Kusano, "Anti-transforming growth factor- $\beta 1$ antibody improves survival rate following partial hepatectomy in cirrhotic rats," Hepatology Research, vol. 24, no. 2, pp. 174-183, 2002. 
[52] P. A. Gruppuso, J. E. Mead, and N. Fausto, "Transforming growth factor receptors in liver regeneration following partial hepatectomy in the rat," Cancer Research, vol. 50, no. 5, pp. 1464-1469, 1990. 